\title{
Positive effects of cyanogenic glycosides in food plants on larval development of the common blue butterfly
}

\author{
Marcel Goverde • Alain Bazin • Marc Kéry • \\ Jacqui A. Shykoff · Andreas Erhardt
}

Received: 9 January 2008 / Accepted: 4 June 2008 / Published online: 4 July 2008

(C) Springer-Verlag 2008

\begin{abstract}
Cyanogenesis is a widespread chemical defence mechanism in plants against herbivory. However, some specialised herbivores overcome this protection by different behavioural or metabolic mechanisms. In the present study, we investigated the effect of presence or absence of cyanogenic glycosides in birdsfoot trefoil (Lotus corniculatus, Fabaceae) on oviposition behaviour, larval preference, larval development, adult weight and nectar preference of the common blue butterfly (Polyommatus icarus, Lycaenidae). For oviposition behaviour there was a female-specific reaction to cyanogenic glycoside content; i.e. some females preferred to oviposit on cyanogenic over acyanogenic plants, while other females behaved in the opposite way. Freshly hatched larvae did not discriminate between the two plant morphs. Since the two plant morphs differed not only in their content of cyanogenic glycoside, but also in $\mathrm{N}$ and water content, we expected these differences to affect larval growth. Contrary to our expectations, larvae feeding on
\end{abstract}

Communicated by Konrad Fiedler.

M. Goverde $\cdot$ A. Erhardt

Department of Integrative Biology,

Section of Conservation Biology, University of Basel,

St Johanns-Vorstadt 10, 4056 Basel, Switzerland

A. Bazin · J. A. Shykoff

Department of Ecology, Systematics and Evolution, CNRS UMR

8079, University of Paris-Sud, 91405 Orsay Cedex, France

\section{Kéry}

Schweizerische Vogelwarte, Institut für Vogelkunde,

Luzernerstrasse 6, 6204 Sempach, Switzerland

Present Address:

M. Goverde $(\bowtie)$

Melchtalstrasse 21, 4102 Binningen, Switzerland

e-mail: marcel.goverde@unibas.ch; marcel.goverde@bluewin.ch cyanogenic plants showed a faster development and stronger weight gain than larvae feeding on acyanogenic plants. Furthermore, female genotype affected development time, larval and pupal weight of the common blue butterfly. However, most effects detected in the larval phase disappeared for adult weight, indicating compensatory feeding of larvae. Adult butterflies reared on the two cyanogenic glycoside plant morphs did not differ in their nectar preference. But a gender-specific effect was found, where females preferred amino acid-rich nectar while males did not discriminate between the two nectar mimics. The presented results indicate that larvae of the common blue butterfly can metabolise the surplus of $\mathrm{N}$ in cyanogenic plants for growth. Additionally, the female-specific behaviour to oviposit preferably on cyanogenic or acyanogenic plant morphs and the female-genotype-specific responses in life history traits indicate the genetic flexibility of this butterfly species and its potential for local adaptation.

Keywords Cyanogenesis - Chemical defence . Genotype-specific responses $\cdot$ Nectar preference . Oviposition

\section{Introduction}

Many plants protect themselves against generalist herbivores by employing an extraordinary array of chemicals to deter them (e.g. Rosenthal and Berenbaum 1991). One such protection system is the ability to produce and accumulate cyanogenic compounds (especially cyanogenic glycosides). This phenomenon, called cyanogenesis, allows the liberation of HCN. It is found in all major vascular plant groups and over $10 \%$ of vascular plant species have developed this protective mechanism (e.g. Bernays and Chapman 1994; 
Jones 1998). The cyanogenic glycosides are often accumulated in the vacuoles and are capable of releasing $\mathrm{HCN}$ after plant tissue damage (Seigler 1991). Although cyanogenesis may protect plants against general herbivores, specialised species can handle this toxic compound, e.g. selective and dynamic sequestration of $\mathrm{HCN}$ in insects by detoxifying it and even metabolising it to make valuable $\mathrm{N}$ available for primary metabolism (Engler et al. 2000).

Plants show a trade-off between investing energy into chemical defences to deter herbivores or into other fitness parameter such as growth or seed production. Some natural populations of plants differ in their levels of chemical defence. One such example is birdsfoot trefoil (Lotus corniculatus L., Fabaceae). Natural populations of L. corniculatus are polymorphic, thus cyanogenic and acyanogenic plant morphs occur (Jones 1988; Bazin et al. 1997). Different insect species feed on L. corniculatus plants, some avoiding toxic plants by choosing acyanogenic morphs, others having the ability to detoxify HCN (Dowd 1988). It has been suggested that the primary role of cyanogenesis is as a feeding inhibitor, and not at the digesting stage (Jones 1988). Therefore, the first question to be investigated is the choice of ovipositing females and young larvae of butterflies, since these are the two stages at which they first select their host plants. Larval choice of host plants has been investigated in several studies. In his review of 23 papers on the defensive function of cyanogenic glycosides, Hruska (1988) found that 53\% of the study organisms, mainly insects, snails and slugs, preferred acyanogenic plants to cyanogenic ones. Thus, we cannot generally say that herbivores prefer acyanogenic host phenotypes. Although insects usually feed on the leaves on which they hatched, they can change their host plant directly if the plant is toxic (Chapman 1990; Ballhorn et al. 2005). For butterfly larvae all possible responses have been shown: larvae choosing less toxic host plants (e.g. Goverde et al. 2001; Ballhorn et al. 2005), larvae choosing more toxic food (e.g. Brattsten et al. 1983), and no differences in their choice (e.g. Zagrobelny et al. 2007).

Beside the choice of host plants shown by the larvae, female choice for oviposition might even be more important, since flying females are more mobile than larvae. After landing on a potential host plant, butterfly females use their forelegs, midlegs, and antennae to assess plant suitability (e.g. Bernays and Chapman 1994). Therefore, females should be able to differentiate between cyanogenic and acyanogenic morphs due to the release of HCN. Females of the pierid butterfly Colias erate poliographys, for example, are stimulated to oviposit by the presence of the cyanogenic glycosides linamarin and lotaustralin (Honda et al. 1997).

The strategies herbivores use to deal with plant secondary compounds are a function of the chemistry of the ingested compounds and the animal's physiological capacity to overcome the effects of these compounds (McArthur et al. 1986). There are different means by which an insect herbivore can handle the chemical defence of plants: avoidance, detoxification of the toxin, resistant target sites, limited penetration, and biochemical conversion or metabolism (Dowd 1988). For cyanogenic glycosides, the latter has been intensively studied. Many insects and also mammalians are known to have the enzyme rhodanese (thiosulphate sulphurtransferase, EC 2.8.1.1), which catalyses sulphate transfer to detoxify cyanide and is therefore a widespread mode of detoxification (e.g. Parsons and Rothschild 1964; Seigler 1991). The effect of cyanogenic glycosides on insect growth has been shown in different studies. Schistocerca gregaria showed reduced feeding and symptoms of intoxication when feeding on highly cyanogenic lima beans (Ballhorn et al. 2005), and a reduction in oviposition was observed for Cyrtomenus bergi feeding on cyanogenic cassava (Riis et al. 2003). However, no or few effects on insect growth can be found when they feed on cyanogenic host plants (Scriber 1978; Schappert and Shore 1999), and the specialised genus Zygaena shows faster development on cyanogenic plants compared to acyanogenic ones (Zagrobelny et al. 2007). Enzymatic detoxification does have an additive cost for co-factors and energy substrates such as ATP or NADPH, therefore, growth of the herbivore might be reduced since energy has to be invested into detoxification mechanisms (Dowd 1988).

Finally, the quality and quantity of food ingested by larvae affects adult fitness. When the quantity of larval food is reduced or the food is of low quality, adults have a reduced life span and/or their oviposition success is reduced (e.g. Slansky 1993). Some of this deficiency can be compensated by amino acid-rich nectar (e.g. Mevi-Schütz et al. 2003; Mevi-Schütz and Erhardt 2005). Thus feeding on toxic plants as larvae can reduce food quality uptake and thereby reduce adult fitness, which on the other hand can be compensated for by a preference for amino acid-rich nectar at the adult stage.

Using the plant-insect system of birdsfoot trefoil $L$. corniculatus L. (Fabaceae) and the moderate polyphagous common blue butterfly Polyommatus icarus Rottemburg (Lepidoptera, Lycaenidae) we addressed the following hypotheses:

1. Females of P. icarus show oviposition preference for acyanogenic $L$. corniculatus plants.

2. Freshly emerged larvae of $P$. icarus prefer acyanogenic over cyanogenic $L$. corniculatus.

3. Larvae of P. icarus feeding on cyanogenic L. corniculatus show slower development than larvae feeding on acyanogenic plants.

4. Butterflies show a stronger preference for amino acidrich nectar when fed cyanogenic plants as larvae than butterflies from larvae fed acyanogenic plants. 


\section{Materials and methods}

\section{Origin of plants}

L. corniculatus plants were collected from meadows at Lardy (south of Paris, France). At this site, both polymorphs-cyanogenic as well as acyanogenic-grow together (A. Bazin, personal observation). For the larval development test (see below), an additional cyanogenic plant was collected at Nenzlingen (south-west of Basel, Switzerland). Different cyanogenic and acyanogenic genotypes were reproduced by cuttings in the greenhouse. After root formation, cuttings were transplanted into a compost soil medium in small plastic pots (approximately $10 \mathrm{~cm}$ diameter). Plants were kept in the greenhouse at the University of Paris (Orsay) and were later transferred to the Botanical Institute at the University of Basel. During winter, plants were kept in pots outside at the Botanical Garden, Basel.

Before using the plants for the experiments described below, plants were tested for cyanide gas production (Feigl and Anger 1966).

\section{Female oviposition test}

The experiment for female oviposition preference was conducted with two different populations of $P$. icarus females. In autumn, females and males of a laboratory population were mated by the method of Schurian (1988). Several males were released into cages $(1.0 \times 0.6 \mathrm{~m}$ and a height of $0.9 \mathrm{~m})$ 1-3 days before females were added. $L$. corniculatus flowers and a yellow sponge soaked in a $20 \%$ sucrose solution were offered as food sources. Additionally, Petri dishes with moistened soil for puddling were placed in the cages. The mating cages were placed in the greenhouse at approximately $28^{\circ} \mathrm{C}$ under a light cycle of $16 / 8 \mathrm{~h}$. To stimulate copulation, air was moistened several times a day with a manual water sprayer. Copulating pairs were removed and females kept in cages of $20 \times 20 \times 40 \mathrm{~cm}$ containing some flowers of $L$. corniculatus and a yellow sponge soaked in a $20 \%$ sucrose solution. In spring of the following year females were captured at different field sites in the northern Swiss Jura mountains on calcareous grasslands. Females were placed in the same cages as described above.

Cages were daily checked for freshly laid eggs. When females started to oviposit, plants which were to be tested were added to the cages. To avoid any optical effects, the plants were cut to have the same structural appearance. Flower buds were removed since some plants had buds and others did not; P. icarus females use inflorescences as well as foliage for oviposition (Ebert 1993). The evening before use, plants were disinfected with $10 \%$ bleach and thoroughly washed with tap water (Briggs 1990). To avoid any position effects, cages were placed in different orientations in the greenhouse under mercury lamps placed $1 \mathrm{~m}$ above the cages to stimulate oviposition (Schurian 1988). Plants were removed after 1 day and eggs laid on them were counted. The newly added plants were repositioned in a different way than in the first set-up to avoid any position effects.

Cyanogenic and acyanogenic L. corniculatus plants used in this experiment were cultured as described above. Young plants were potted in 500-ml pots with greenhouse soil and kept for at least 2 months in the greenhouse at $24 / 16^{\circ} \mathrm{C}$ night/day temperature. Just before the experiment, plants were tested for cyanide gas production (Feigl and Anger 1966).

Oviposition data were $\log (\mathrm{x}+1)$ transformed and analysed using a repeated measures mixed model in GenStat 9.1 (Welham and Thompson 2006). We used a first-order autoregressive structure for the correlation among measurements within females over time to account for the non-independence of measurements of the same female over successive time-points. In addition, we fitted a random female by cyanide effect to test for a female-specific response to cyanide. Both this random effect and the autocorrelation were tested by conducting a likelihood ratio test between a model that contained that effect (i.e. the autocorrelation or the female by cyanide random effect, respectively) and another that did not. Under the null hypothesis, the difference in the deviance between these two models is $\chi^{2}$ distributed with $1 d f$. We could not fit a random female main effect since a model that contained this effect failed to converge. A test of a female random effect in a model that did not contain the autocorrelation (and did converge) suggested the female main effect was not significant $\left(\chi^{2}=1.007, P=0.316, d f=1\right)$. We used Wald tests to test the fixed effects.

\section{Larval preference test}

Females of $P$. icarus Rottemburg (Lepidoptera, Lycaenidae) were captured at different sites in the northern Swiss Jura mountains and kept in cages in the greenhouse for oviposition (for further details on oviposition see Goverde et al. 1999). The larval preference test was performed with freshly hatched larvae from female butterflies of the first generation in May/June $(n=6)$ and with the second generation in August $(n=12)$. A replication unit consisted of two fresh sprigs of a specific genotype of $L$. corniculatus (one cyanogenic and one acyanogenic) each placed into a $1.5-\mathrm{ml}$ Eppendorf tube full of tap water with a pierced cap. The two tubes were placed in a Petri dish and the sprigs were arranged randomly. Four freshly emerged larvae originating from different females were placed on the opposite side of the sprigs in the Petri dish. The Petri dish was covered by 
a nylon mesh to avoid larval escape and the Petri dish lid to minimise dehydration. Petri dishes were placed in the lab at room temperature. After 4 days, surviving larvae were counted and the sprigs were removed. Each leaf was placed under an overhead transparency and the contour of the leave as well as the eaten area was drawn. Then the remaining area as well as the total area was measured using a planimeter (LI-3100 area meter; LI-COR, Lincoln, Neb.). To reduce measuring errors, each leaf was measured 3 times and the mean was used. The eaten area per larva was calculated as the difference between total and remaining area divided by the number of surviving larvae. Eaten area per larva was analysed by a full-factorial two-way ANOVA with the factors Generation $(d f=1)$ and Cyanide $(d f=1)$ and their interaction. Analyses were performed with SAS JMP V.3.2.6 (SAS 1995) and employ type III sums of squares.

\section{Larval development test}

Cuttings of eight different $L$. corniculatus genotypes (four acyanogenic and four cyanogenic) were planted in February in the greenhouse at the University of Basel. After 15 days of growth, plants were transferred to $760-\mathrm{ml}$ pots containing greenhouse soil:quartz sand (4:1). In total six replicates per plant genotype were used resulting in 48 pots. Plants were randomly placed on two tables in the greenhouse and watered when necessary.

In this experiment, eggs from three different $P$. icarus females captured in the northern Swiss Jura mountains were used (see above). After hatching, six larvae per female were placed into a Petri dish containing shoots either of a cyanogenic or an acyanogenic $L$. corniculatus sprig. On reaching their third larval instar $\left(\mathrm{I}_{3}\right)$, larvae were weighed individually and placed on the $L$. corniculatus genotype on which they had been feeding before. Thus for each of the eight plant genotypes (four cyanogenic and four acyanogenic), there were two replicates per female genotype. Plants were covered with a cage made out of mellinex foil $(9.5 \times 9.5 \times 30 \mathrm{~cm})$ with holes of $8 \mathrm{~cm}$ on each side, covered by a nylon mesh and placed in the greenhouse. After feeding for 8 days on the plants, larvae were removed, weighed and placed again on their host plant until pupation. Pupae were collected and weighed, and singly placed in one of 18 compartments of a plastic box $(21 \times 12 \mathrm{~cm})$ with a nylon web floor. Boxes were placed in the greenhouse $5 \mathrm{~cm}$ above a pan with water to maintain humidity. Boxes were checked daily for emerging adults. Date of emergence was noted and the total development time calculated (from larval emergence to butterfly emergence). After butterflies had emptied their gut, they were weighed and tested for amino acid preference (see below).

After removing all pupae, plant characteristics were measured. To analyse cyanogenic glycoside content, six leaves of equal size from each plant were removed, frozen in liquid $\mathrm{N}$ and stored at $-80^{\circ} \mathrm{C}$ until analysis (for further details see Goverde et al. 1999). To determine leaf water content, some leaves of each plant were harvested and water content was measured as the proportional difference between fresh and dry leaf weight (dried at $60^{\circ} \mathrm{C}$ for at least $48 \mathrm{~h}$ ). Remaining plants (aboveground biomass) were harvested, weighed and dried. Total aboveground biomass was calculated as sum of the leaf dry weight used for water content and remaining dried plants. Finally, $\mathrm{N}$ and $\mathrm{C}$ concentrations were determined from dried leaves using a CHN analyser (model 932; LECO Instruments, St Joseph, Mich.), which uses a combustion procedure.

For statistical analysis, butterfly life history traits were analysed using a full-factorial ANOVA with the main factors Cyanide $(d f=1)$, Female genotype $(d f=2)$ and Sex $(d f=1)$. Analyses were performed with SAS JMP version 3.2.6 (SAS 1995) and employed type III sums of squares. A stepwise model reduction of this full model was employed, with the highest order interactions removed and the least significant effect always first (Crawley 1993). Model reduction stopped when $P<0.1$ or when no further interaction term could be removed. When necessary, data were transformed as described below. Plant characteristics were analysed by $F$-tests, except for cyanogenic glycoside concentration for which a $\chi^{2}$-test was used since the data were heteroscedastic. Statistical tests were performed using SAS JMP version 3.2.6 (SAS 1995).

\section{Nectar-preference testing}

Butterflies from the pot experiment described above were used to investigate their preference for amino acid-rich nectar versus a nectar mimic without amino acids (for further details see Mevi-Schütz et al. 2003). Prior to testing, butterflies were pre-fed a balanced sugar solution to bring them to the same nutritional level. Then the test solution was offered to the butterflies in $0.5-\mu 1$ droplets extruded from the tip of a Hamilton syringe $(10 \mu \mathrm{l}$, gas tight, no. 701 , $75 \mathrm{~N}$ ) according to the method described by Mevi-Schütz et al. (2003). The preference test consisted of five trials. In each trial the two nectar mimics were each offered once and the order of this presentation was randomly chosen.

For data analysis the difference between droplets accepted from the amino acid-containing nectar mimics and the non-amino acid-containing nectar mimics was calculated. Thus, positive values indicate a preference for the nectar mimic containing amino acid, whereas negative values indicate a preference for nectar mimics without amino acids. This parameter was then analysed using a full-factorial ANOVA as described above, with the main factors Cyanide $(d f=1)$, Female genotype $(d f=2)$ and Sex $(d f=1)$. Again a stepwise model reduction of this full 
model was employed as described above. Statistical tests were performed using SAS JMP version 3.2.6 (SAS 1995).

\section{Results}

Female oviposition test

In total 16 females were tested; eight from the lab population and eight from the field population. The females oviposited between 2 and 6 days, so that in total 55 tests were performed (Fig. 1). Between 1 and 62 eggs (mean $=22.6 \pm 2.6$ eggs) were counted per test. In total, 1,245 eggs were counted over all tests; 565 eggs were found on cyanogenic and 680 eggs on acyanogenic Lotus genotypes. Using the statistical model described above, there was significant variation among females in their response to the cyanogenic glycoside concentration of plants (test of the random factor female by cyanide: $\chi^{2}=4.413, P=0.036, d f=1$; Fig. 2 ), and there was also a significant autocorrelation among successive measurements within the same female (test of the first-order autocorrelation among successive time points: $\chi^{2}=5.990, P=0.014$, $d f=1)$. When fixed effects were tested within that model, there was only a significant linear positive time trend (Table 1), while the other fixed effects were not significant. For instance, the two different populations used did not differ in their response to cyanogenic and acyanogenic plants, and there was also no significant population-specific reaction to cyanogenic glycoside concentration (Table 1).

\section{Larval preference test}

Larvae of the first generation consumed significantly more of their host plant than larvae of the second generation $\left(F_{1,32}=11.00, P=0.002\right.$; Fig. 3$)$. However, they did not distinguish between cyanogenic and acyanogenic leaves

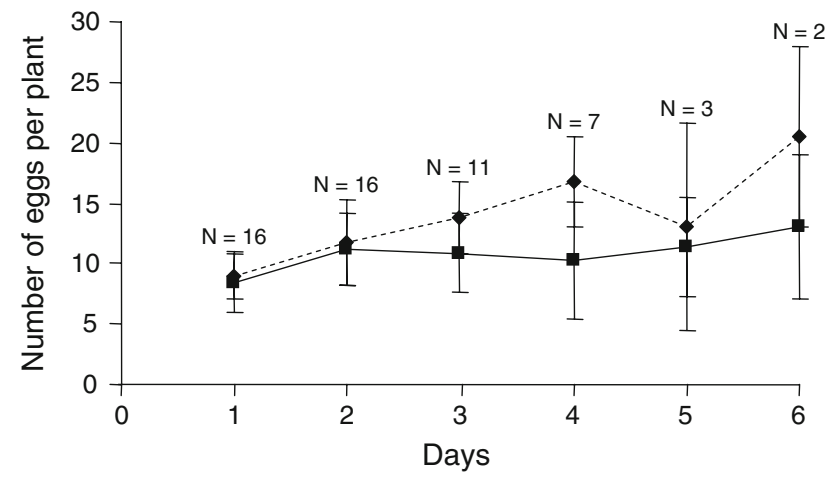

Fig. 1 Mean number ( \pm SEM) of eggs oviposited on cyanogenic (squares, solid line) or acyanogenic (rhomboids, dotted line) Lotus corniculatus plants. $N$ Number of females ovipositing on the according day

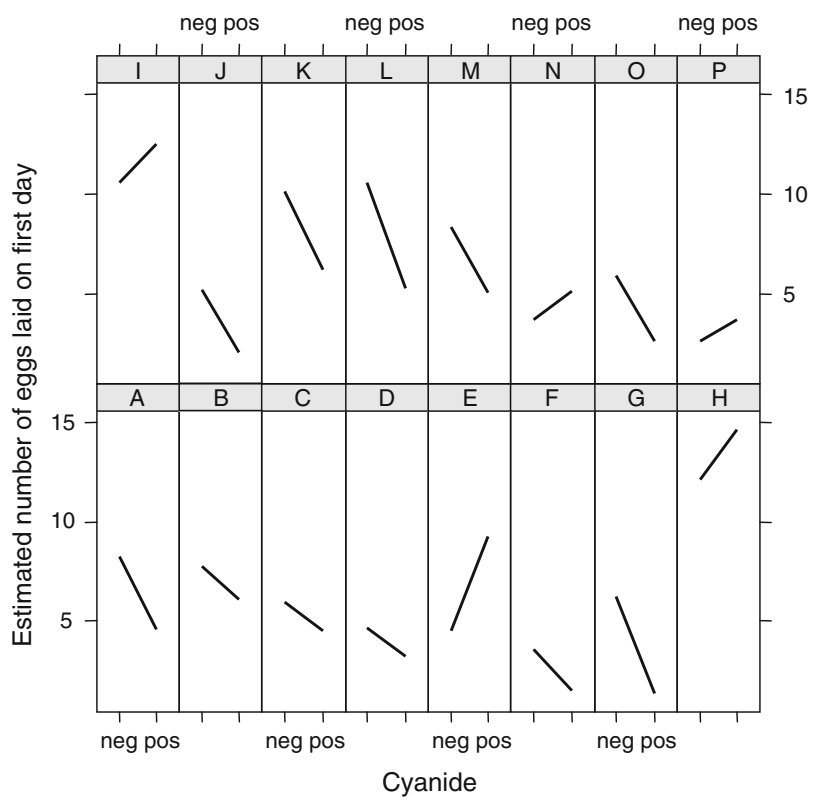

Fig. 2 Female-specific cyanide effect as estimated under the mixed model (cf. description in text). Bottom row Lab population (females $A$ $H$ ), top row field population (females $I-P$ ). neg negative, pos positive

Table 1 Effects on the number of eggs laid by Polyommatus icarus $\left(\log _{10}+1\right.$ transformed) in experimental treatments. All terms have $1 d f$

\begin{tabular}{lrrr}
\hline Fixed effects & Estimate (SE) & Wald $\chi^{2}$ & $P$ \\
\hline Population (lab vs. field) & $-0.30(0.39)$ & 0.12 & 0.731 \\
Day (linear trend) & $0.19(0.08)$ & 5.58 & 0.018 \\
Cyanide & $-0.28(0.30)$ & 1.85 & 0.174 \\
Population by cyanide & $0.01(0.40)$ & $<0.01$ & 0.975 \\
\hline
\end{tabular}

$\left(F_{1,32}=0.76, P=0.39\right)$. The first generation of larvae tended to prefer cyanogenic over acyanogenic leaves, while the opposite effect was found for the second generation (Fig. 3). However, this interactive effect was not significant $\left(F_{1,32}=2.47, P=0.13\right)$.

Larval development test

Larvae of $P$. icarus performed better when feeding on cyanogenic L. corniculatus plants. Larval, pupal and adult weights were increased and development time was reduced when larvae fed on cyanogenic plants (Fig. 4; Table 2). The origin of the larvae (Female genotype) affected larval weight, pupal weight and development time but did not affect adult weight (Table 2). There was also a significant interaction of Female genotype and Sex (Table 2) regarding larval weight after 8 days and pupal weight, indicating that differences between males and females were not the same for all female genotypes. For example, larval weight after 8 days did not differ between males and females in female 


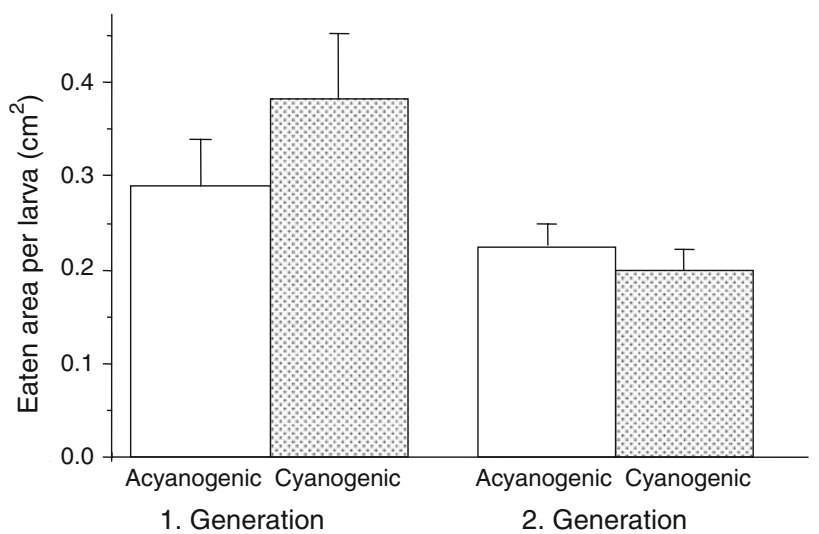

Fig. 3 Area of acyanogenic and cyanogenic L. corniculatus leaves eaten by larvae of Polyommatus icarus of the first (spring) and second (late summer) generation. Mean \pm SEM

genotype 1 and female genotype 3, while males of female genotype 2 were clearly heavier than females (Fig. 5). In contrast, pupal weight of female genotype 1 individuals did not differ between gender, while in female genotype 2 and female genotype 3, males were heavier than females (Fig. 5). However, a general effect of gender (sex) only appeared for pupal weight (Table 2), where males were heavier than females (males $=110.1 \pm 3.1 \mathrm{mg}$, females $=97.0 \pm 2.8 \mathrm{mg}$ ). Finally, all these effects disappeared for emerged butterflies (adult weight; Table 2).

Cyanogenic $L$. corniculatus plants showed a mean cyanogenic glycoside concentration of $2.82 \pm 0.16 \mathrm{mg} / \mathrm{g}$ with the lowest concentration being $1.48 \mathrm{mg} / \mathrm{g}$ and the highest being $4.91 \mathrm{mg} / \mathrm{g}$ (Table 3). Furthermore, all other measured plant characteristics were significantly different between the two genotypes. For cyanogenic plants water content, total biomass and $\mathrm{C} / \mathrm{N}$-ratio were lower compared to acyanogenic plants, while the $\mathrm{N}$ content was higher (Table 3).

\section{Nectar-preference testing}

The cyanogenic glycoside content of the larval food source did not have any influence on adult preferences for amino acid-rich nectar mimics (cyanogenic $=1.3 \pm 0.2, n=24$; acyanogenic $\left.=0.5 \pm 0.3, n=22 ; \quad F_{1,39}=0.09, \quad P=0.77\right)$.
Fig. 4 Life history traits of $P$. icarus separated by female $(\mathrm{F})$ origin ( F $1-F 3)$ and feeding on acyanogenic and cyanogenic $L$. corniculatus plants.

Mean \pm SEM
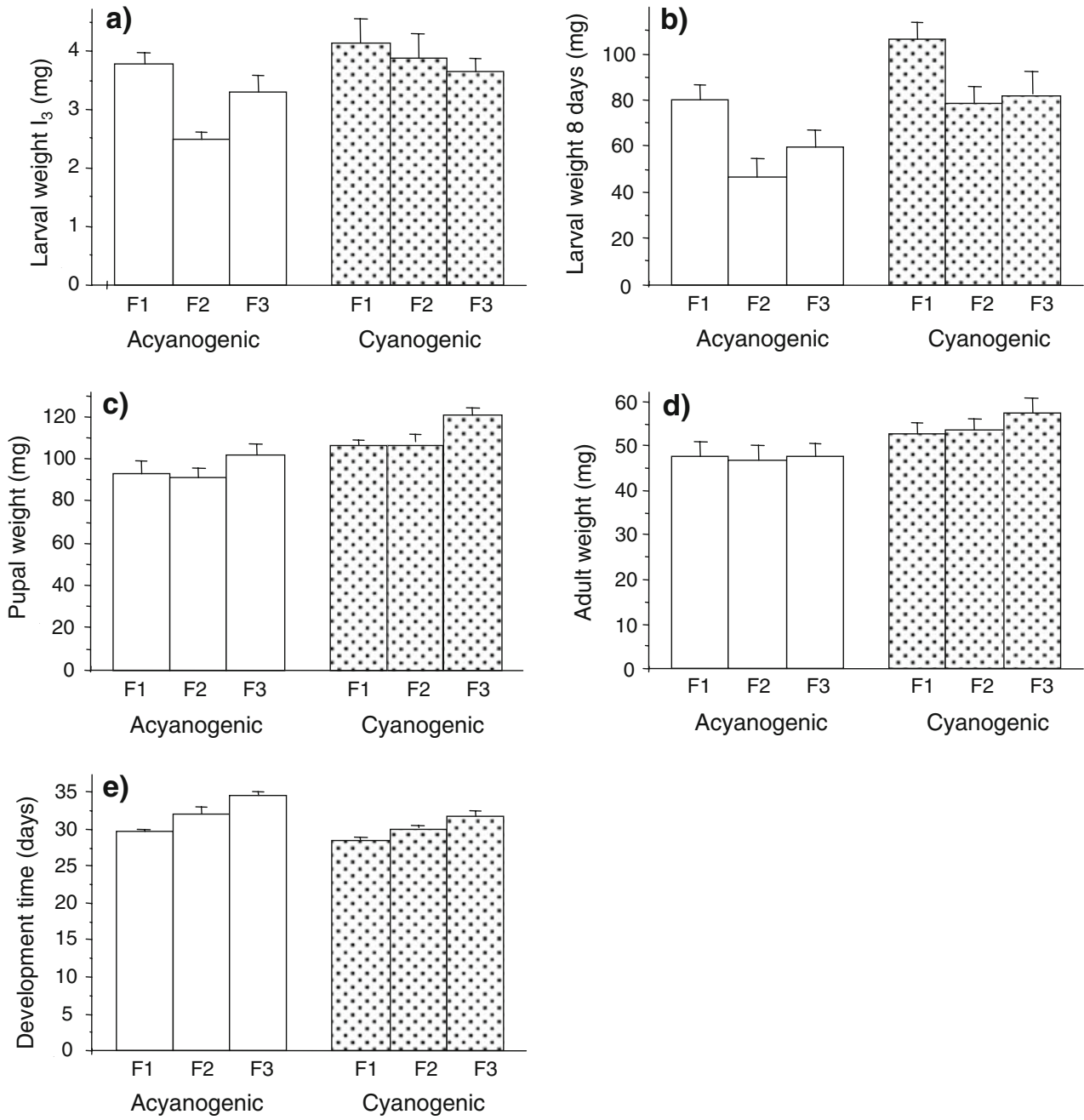
Table 2 Results of the ANOVA [type III sum of squares; main factors Cyanide $(C N)$, Female genotype $(F G)$, Sex; reduced models, cf. description in text] on different life history traits of $P$. icarus $[n=47$ in all cases (one larva died at the pupal stage and was therefore omitted from the analysis), except for adult weight where $n=46$ since one butterfly eclosed but died, thus its weight could not be properly determined]

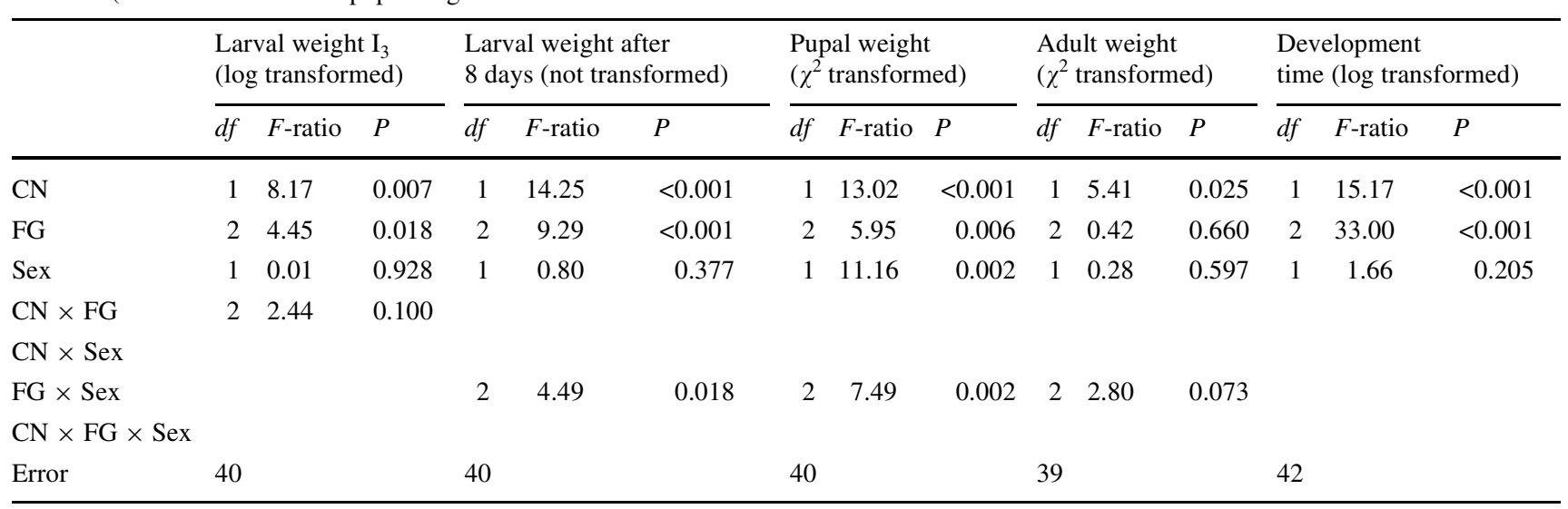
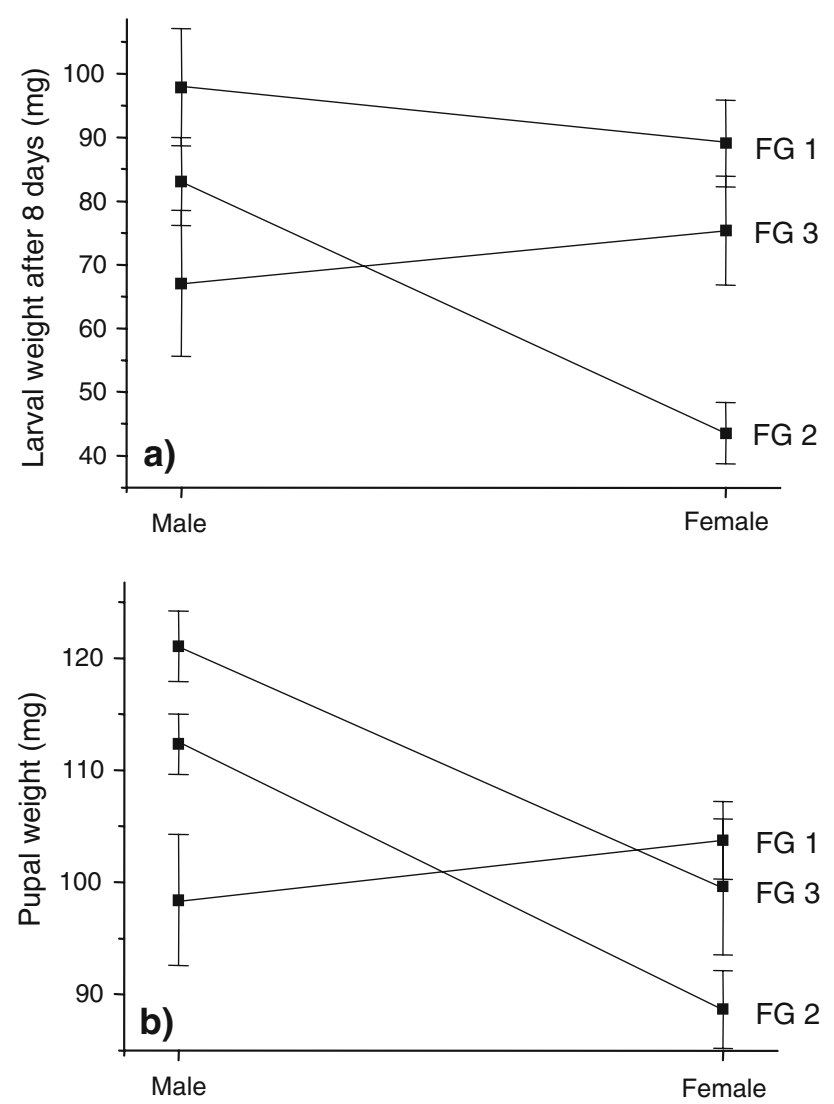

Fig. 5 Differences between males and females of P. icarus for a larval weight after 8 days, and $\mathbf{b}$ pupal weight depending on the origin of larvae (Female genotype, $F G$ ). Mean \pm SEM

The only effect in nectar preference was found between gender $\left(F_{1,39}=45.12, P<0.001\right)$, where females clearly preferred amino acid-rich nectar mimics $(1.8 \pm 0.2, n=22)$ compared to males $(0.1 \pm 0.1, n=24)$. Finally, female genotype did not have any effect on nectar preference $\left(F_{2,39}=0.08, P=0.93\right)$.

\section{Discussion}

Preference for plants containing cyanogenic glycosides

In our first two hypotheses we predicted that ovipositing females and freshly hatched larvae would choose the less toxic plant material, i.e. acyanogenic over cyanogenic $L$. corniculatus genotypes. We did not find such an overall preference. Freshly emerged larvae consumed the same amount of leaf material of both genotypes. This could have been due to an inability to discriminate between or detect cyanogenic and acyanogenic food. Detection of non- or less toxic food has been shown for other larvae (Goverde et al. 2001), and there is an indication that molluscs and insects prefer acyanogenic over cyanogenic plants (Jones 1998), but a general trend is not obvious (Hruska 1988). P. icarus larvae may show an indifferent response since they can detoxify cyanide (Parsons and Rothschild 1964; Beesley et al. 1985), and therefore no evolutionary pressure exists on this trait. An observed lack of food-plant discrimination could also be due to freshly hatched larvae having to eat what they find first, rather than choosing another food source. In the present study, we allowed the larvae to feed on the different plant genotypes for 3 days. Thus, larvae should have had enough time to show a potential feeding preference.

The spring generation of freshly emerged larvae consumed more plant material than the late summer generation. This might have been caused by an over-wintering effect, whereby the spring generation have less reserves from their mothers, or by may be due to differences in nutritional quality or texture of phenologically young plant material (according to the plant phenological age hypothesis; e.g. Scheirs et al. 2002).

There was no overall effect of cyanogenesis on the oviposition behaviour of $P$. icarus females. However, there 
Table 3 Mean \pm SEM for the plant characteristics of Lotus corniculatus from the pot experiment. All data were analysed by $F$-test except for cyanogenic glycoside concentration (cyanide concentration) for which a $\chi^{2}$-test was used (cf. description in text). d.w. Dry weight

\begin{tabular}{lclllll}
\hline & $n$ or $d f$ & Water content $(\%)$ & Biomass (d.w., g) & N content $(\%$ d.w.) & C/N ratio & Cyanide concentration (mg/g) \\
\hline Acyanogenic & 48 & $80.9 \pm 0.2$ & $3.02 \pm 0.24$ & $3.60 \pm 0.11$ & $13.29 \pm 0.39$ & $0.02 \pm 0.01$ \\
Cyanogenic & 48 & $78.9 \pm 0.5$ & $2.05 \pm 0.14$ & $4.03 \pm 0.10$ & $11.70 \pm 0.32$ & $2.82 \pm 0.16$ \\
$F$ - or $\chi^{2}$-value & 1 & 13.38 & 11.69 & 8.80 & 10.15 & 35.28 \\
$P$-value & & $<0.001$ & 0.001 & 0.005 & 0.003 & $<0.001$ \\
\hline
\end{tabular}

was an effect at the level of the female genotype (interaction between female genotype and cyanogenesis). Certain female genotypes preferred acyanogenic over cyanogenic L. corniculatus plants, while other female genotypes preferred cyanogenic plant morphs. This finding implies a certain genetic flexibility for the presence of cyanogenesis in the larval host, and thereby might lead to local adaptation. Local adaptation has been investigated for P. icarus by using two different larval host plant species and two different-geographically widely separated—butterfly populations (Bergstrom et al. 2004). No difference in oviposition preference or larval performance between the populations from the two different areas could be detected. However, this latter experiment addressed the level of different host plant species, not different genotypes of the same host plant species as in the present study. The two populations used (lab population and field population) in the present study did not show different effects of cyanogenesis, therefore, the results are in accordance with the findings of Bergstrom et al. (2004). Finally, P. icarus is a highly plastic species; larvae feed on several species within the Fabaceae and adults use many different food and oviposition sources (Ebert 1993). Furthermore, flower buds were removed before oviposition behaviour was tested, and since $P$. icarus females prefer to oviposit on inflorescences rather than on foliage (K. Fiedler, personal communication), and flowers might have higher levels of cyanogenic glycosides than leaves, the observed effect could be even more pronounced.

Insect development on cyanogenic and acyanogenic plants

In our third hypothesis we predicted that larvae feeding on acyanogenic $L$. corniculatus would develop better than those feeding on cyanogenic plants. Unexpectedly, the contrary was found. Larvae feeding on cyanogenic plants developed faster, showed higher weights, and pupal and adult weights were higher compared to larvae feeding on acyanogenic plants. Different factors may account for this effect. Since larvae did not show any preference for cyanogenesis in the choice experiment, they were not deterred by the cyanide. $P$. icarus is know to possess the enzyme rhodanese which catalyses sulphate transfer to detoxify cyanide (e.g. Parsons and Rothschild 1964; Seigler 1991). It is therefore possible, if not likely, that they could use the surplus of $\mathrm{N}$ from cyanogenic plants and metabolise it into biomass. Such an effect has been shown for Heliconius sara which can sequester cyanogenic glycoside and metabolise it (Engler et al. 2000) and for several Zygaenidae which can sequester or even biosynthesize cyanogenic compounds such as linamarin and/or lotaustralin (e.g. Nahrstedt 1988; Zagrobelny et al. 2004). In the subfamily of Polyommatinae there are species which can sequester cyanogenic compounds (Nahrstedt 1988; Zagrobelny et al. 2004). These compounds are mostly stored in those parts of the body which predators first come into contact with (skin, cuticular cavities, haemolymph, wings and spines; Nahrstedt 1988; Zagrobelny et al. 2004). Furthermore, $P$. icarus can also sequester flavonoids, which are mainly incorporated in wing patterns (Knüttel and Fiedler 2001; Burghardt et al. 2001). These wing patterns are important for mate-searching since flavonoid-rich female butterflies are more intensively visited by males than those with little or no flavonoids (Burghardt et al. 2000).

For all the plant characteristics measured, we found differences between the two $L$. corniculatus genotypes. Probably the most important factor is the $\mathrm{N}$ content which was approximately $10 \%$ higher in cyanogenic compared to acyanogenic plants. This higher $\mathrm{N}$ content in cyanogenic plants could result from $\mathrm{N}$ allocated to cyanogenic glycosides. In Eucalyptus up to $20 \%$ of the leaf $\mathrm{N}$ can be allocated to the cyanogenic glycoside prunasin (Gleadow and Woodrow 2000). Since N is generally known to be the most important nutritional factor in plant-herbivore interactions (Mattson 1980), the higher N content of cyanogenic plants might be responsible for the better larval performance observed in the present study.

Increased development on cyanogenic plants may also be due to the phagostimulating effect of cyanogenic glycosides which is known for some insects (Bernays and Chapman 1994). Since $P$. icarus is not negatively affected by cyanogenic glycosides, the release of cyanide or the cyanogenic glycoside itself could act as a phagostimulant.

The origin of the females (female genotype) affected all insect growth parameters except adult weight. Genotypespecific differences in $P$. icarus have been found before (e.g. Goverde et al. 2000, 2004) and show the genetic flexibility of this species. Furthermore, there was an interactive 
effect of female genotype and sex (gender) for larval and pupal weight. In some female genotypes no differences between males and females were evident, while for others males were heavier than females, indicating faster development for males (i.e. protandry). However, it remains unclear why this effect is evident for pupal weight and then disappears, or is at least very weak, for adult weight. Sex differences in adult weight and size have been shown before and resulted from the use of different larval host plants or the presence/absence of mutualistic ant partners (Burghardt et al. 2001; Fiedler and Hölldobler 1992).

\section{Adult nectar preference}

In our fourth hypothesis we predicted a preference for amino acid-rich nectar for adults of larvae which fed on cyanogenic plants. According to the previous findings indicating that larvae developed better on cyanogenic plants (see above), our hypothesis should actually be reversed, i.e. if larvae feed on food of lower quality (in this case lower $\mathrm{N}$ content, thus acyanogenic plants), as adult they should prefer amino acid-rich nectar. However, in the present study no preference which depended on larval food source was found. The difference in $\mathrm{N}$ content between cyanogenic and acyanogenic plants may not have been strong enough to cause nectar preference. Alternatively, the $\mathrm{N}$ content per se was high enough in both plant genotypes, therefore adults did not need to compensate for $\mathrm{N}$ deficiency with a preference for amino acid-rich nectar. However, the $\mathrm{N}$ content of larval food plants can affect adult feeding behaviour. Such an effect was found with fertilized plants where adults from larvae feeding on fertilized plants did not discriminate among amino acid-rich nectar and sugar solution, while adults from larvae grown on non-fertilized plants did (Mevi-Schütz et al. 2003). In this case the difference between fertilized and non-fertilized plants was $38 \%$, while in the present experiment the difference is only $10 \%$.

Nevertheless, we found a difference in nectar preference between males and females. Males were indifferent, whereas females preferred amino acid-rich nectar. This is likely due to the higher $\mathrm{N}$ needs of females for egg laying and has been show in other butterfly species (e.g. MeviSchütz and Erhardt 2005).

\section{Conclusion}

We investigated the effect of cyanogenesis in L. corniculatus plants on oviposition, larval choice behaviour, larval development and nectar preference of $P$. icarus. Surprisingly, larval performance was better on cyanogenic plants, which was most likely due to the higher $\mathrm{N}$ content of cyanogenic compounds. Furthermore, we found a genotype-specific choice behaviour of females for oviposition on the two plant geno- types. These findings show that $P$. icarus is well adapted to cyanogenesis in $L$. corniculatus, and that local adaptation might be relevant for this species. In this study the common blue butterfly has once again shown its intra-specific flexibility, which makes it an easily adaptable species and may explain its widespread and common occurrence.

Acknowledgements We are especially grateful to Kathrin Schweizer, Daniel Bretscher and Olivier Bignucolo for technical support and two anonymous referees for critical comments on the manuscript. This research was supported by grants from the Swiss Priority Program Environment of the Swiss National Science Foundation to A. Erhardt (No. 5001-044622/1). All experiments conducted in this study comply with French and Swiss federal laws.

\section{References}

Ballhorn DJ, Lieberei R, Ganzhorn JU (2005) Plant cyanogenesis of Phaseolus lunatus and its relevance for herbivore-plant interaction: the importance of quantitative data. J Chem Ecol 31:14451473

Bazin A, Blaise S, Cartier D (1997) Polymorphism of two defence mechanisms in Lotus corniculatus L. (Fabaceae); relation with abiotic factors. Acta Bot Gallica 144:433-442

Beesley SG, Compton SG, Jones DA (1985) Rhodanese in insects. J Chem Ecol 11:45-50

Bergstrom A, Nylin S, Nygren GH (2004) Conservative resource utilization in the common blue butterfly-evidence for low costs of accepting absent host plants? Oikos 107:345-351

Bernays EA, Chapman RF (1994) Host-plant selection by phytophagous insects. Chapman \& Hall, New York

Brattsten LB, Samuelian JH, Long KY, Kincaid SA, Evans CK (1983) Cyanide as a feeding stimulant for the southern army worm, Spodoptera eridania. Ecol Entomol 8:125-132

Briggs MA (1990) Relation of Spodoptera eridania choice to tannins and protein of Lotus corniculatus. J Chem Ecol 16:1557-1564

Burghardt F, Knüttel H, Becker M, Fiedler K (2000) Flavonoid wing pigments increase attractiveness of female common blue (Polyommatus icarus) butterflies to mate-searching males. Naturwissenschaften 87:304-307

Burghardt F, Proksch P, Fiedler K (2001) Flavonoid sequestration by the common blue butterfly Polyommatus icarus: quantitative intraspecific variation in relation to larval hostplant, sex and body size. Biochem Syst Ecol 29:875-889

Chapman RF (1990) Food selection. In: Chapman RF, Joern A (eds) Biology of grasshoppers. Wiley, New York, pp 39-72

Crawley MJ (1993) GLIM for ecologists. Blackwell, Oxford

Dowd PF (1988) Detoxification of plant substances by insects. In: Morgan ED, Mandava NB (eds) CRC handbook of natural pesticides. Insect attractions and repellents, vol IV. CRC, pp 181-225

Ebert G (1993) Die Schmetterlinge Baden-Württembergs. Band 2. U1mer, Stuttgart

Engler HS, Spencer KC, Gilbert LE (2000) Preventing cyanide release from leaves. Nature 406:144-145

Feigl F, Anger V (1966) Replacement of benzidine by copper ethylacetoacetate and tetrabase as spoot-test for hydrogen cyanide and cyanogen. Analyst 91:282-284

Fiedler K, Hölldobler B (1992) Ants and Polyommatus icarus immatures (Lycaenidae) — sex-related development benefits and cost of ant attendance. Oecologia 91:468-473

Gleadow RM, Woodrow IE (2000) Temporal and spatial variation in cyanogenic glycosides in Eucalyptus cladocalyx. Tree Physiol 20:591-598 
Goverde M, Bazin A, Shykoff JA, Erhardt A (1999) Influence of leaf chemistry of Lotus corniculatus (Fabaceae) on larval development of Polyommatus icarus (Lepidoptera, Lycaenidae): effects of elevated $\mathrm{CO}_{2}$ and plant genotype. Funct Ecol 13:801-810

Goverde M, van der Heijden MGA, Wiemken A, Sanders IR, Erhardt A (2000) Arbuscular mycorrhizal fungi influence life history traits of a lepidopteran herbivore. Oecologia 125:362-369

Goverde M, Granados J, Erhardt A (2001) Host-plant selection in three different moth larvae. Mitt Schweiz Ent Ges 74:143-150

Goverde M, Erhardt A, Stocklin J (2004) Genotype-specific response of a lycaenid herbivore to elevated carbon dioxide and phosphorus availability in calcareous grassland. Oecologia 139:383-391

Honda K, Nishii W, Hayashi N (1997) Oviposition stimulants for sulfur butterfly, Colias erate poliographys: cyanoglucosides as synergists involved in host preference. J Chem Ecol 23:323-331

Hruska AJ (1988) Cyanogenic glucosides as defense compunds: a review of the evidence. J Chem Ecol 14:2213-2217

Jones DA (1988) Cyanogenesis in animal-plant interactions. In: Evered D, Harnett S (eds) Cyanide compounds in biology. Wiley, Chichester, pp 151-165

Jones DA (1998) Why are so many food plants cyanogenic? Phytochemistry 47:155-162

Knüttel H, Fiedler K (2001) Host-plant-derived variation in ultraviolet wing patterns influences mate selection by male butterflies. J Exp Biol 204:2447-2459

Mattson WJ (1980) Herbivory in relation to plant nitrogen content. Annu Rev Ecol Syst 11:119-161

McArthur C, Hagerman AE, Robbins CT (1986) Physiological strategies of mammalian herbivores against plant defenses. In: Miller JR, Miller TA (eds) Insect-plant interactions. Springer, New York, pp 103-114

Mevi-Schütz J, Erhardt A (2005) Amino acids in nectar enhance butterfly fecundity: a long-awaited link. Am Nat 165:411-419

Mevi-Schütz J, Goverde M, Erhardt A (2003) Effects of fertilization and elevated $\mathrm{CO}_{2}$ on larval food and butterfly nectar amino acid preference in Coenonympha pamphilus L. Behav Ecol Soc 54:36-43

Nahrstedt A (1988) Cyanogenesies and the role of cyanogenic compounds in insects. In: Evered D, Harnett S (eds) Cyanide compounds in biology. Wiley, Chichester, pp 131-144

Parsons J, Rothschild M (1964) Rhodanese in the larva and pupa of the common blue butterfly (Polyommatus icarus Rott.) (Lepidoptera). Entomol Gaz 15:58-59
Riis L, Bellotti AC, Bonierbale M, O’Brien GM (2003) Cyanogenic potential in cassava and its influence on a generalist insect herbivore Cyrtomenus bergi (Hemiptera: Cydnidae). J Econ Entomol 96:1905-1914

Rosenthal GA, Berenbaum MR (1991) Herbivores. Their interactions with secondary plant metabolites. Academic Press, San Diego

SAS (1995) JMP user's guide, version 3.1. SAS, Cary

Schappert PJ, Shore JS (1999) Effects of cyanogenesis polymorphism in Turnera ulmifolia on Euptoieta hegesia and potential Anolis predators. J Chem Ecol 25:1455-1479

Scheirs J, De Bruyn L, Verhagen R (2002) Seasonal changes in leaf nutritional quality influence grass miner performance. Ecol Entomol 27:84-93

Schurian KG (1988) Revision der Lysandra-Gruppe des genus Polyommatus Latr. (Lepidoptera: Lycaenidae). University Frankfurt am Main, Frankfurt

Scriber JM (1978) Cyanogenic glycosides in Lotus corniculatus. Their effect upon growth, energy budget, and nitrogen utilization of the southern armyworm, Spodoptera eridania. Oecologia $34: 143-155$

Seigler DS (1991) Cyanide and cyanogenic glycosides. In: Rosenthal GA, Berenbaum MR (eds) Herbivores. Their interaction with secondary plant metabolites. Academic Press, San Diego, pp 35-78

Slansky F (1993) Nutritional ecology: the fundamental quest of nutrients. In: Stamp NE, Casey TM (eds) Caterpillars: ecological and evolutionary constraints on foraging. Chapman \& Hall, New York, pp 29-91

Welham SJ, Thompson R (2006) REML analysis of mixed models. In: Payne RW, Harding SA, Murray DA, Soutar DM, Baird DB, Welham SJ, Kane AF, Gilmour AR, Thompson R, Webster R, Tunnicliffe Wilson G (eds) The Guide to GenStat Release 9. VSN International, Hemel Hempstead, UK, pp 607-704

Zagrobelny M, Bak S, Rasmussen AV, Jorgensen B, Naumann CM, Moller BL (2004) Cyanogenic glucosides and plant-insect interactions. Phytochemistry 65:293-306

Zagrobelny M, Bak S, Ekstrom CT, Olsen CE, Moller BL (2007) The cyanogenic glucoside composition of Zygaena filipendulae (Lepidoptera: Zygaenidae) as effected by feeding on wild-type and transgenic lotus populations with variable cyanogenic glucoside profiles. Insect Biochem Mol Biol 37:10-18 